\title{
Procedure Agent Reported Name
}

National Cancer Institute

\section{Source}

National Cancer Institute. Procedure Agent Reported Name. NCI Thesaurus. Code C162119.

The name of a medical product, practice, or application reported in a clinical trial. 